\title{
Turismo cultural e interpretação do patrimônio na cidade de Diamantina - Minas Gerais/Brasil
}

\section{Luciana Aparecida Felicidade* Elcione Luciana Silva** \\ Universidade de Coimbra (Portugal)}

\begin{abstract}
Resumo: A cidade de Diamantina em Minas Gerais/Brasil teve o seu conjunto arquitetônico tombado pelo Instituto do Patrimônio Histórico e Artístico Nacional (IPHAN) em 1938 e em 1999 recebeu o titulo de Patrimônio Cultural da Humanidade pela UNESCO. Evidentemente, após este reconhecimento surgiram novos desafios advindos da relação entre patrimônio e turismo no sentido de cumprir com o objetivo do turismo cultural que é o de promover o encontro entre o turista e o patrimônio cultural. O objetivo desta pesquisa foi abordar a importância da interpretação do patrimônio, identificando quais são as estratégias existentes que facilitam a proximidade do turista com o patrimônio local, tendo como estudo de caso a cidade de Diamantina. Para tal, além de revisão bibliográfica sobre a relação turismo e patrimônio, realizou-se pesquisa de demanda turística para identificar o grau de satisfação do turista nos monumentos visitados. A pesquisa é de caráter quantitativa-descritiva com abordagem qualitativa.
\end{abstract}

Palavras-chave: Turismo cultural; interpretação do patrimônio; Diamantina/MG; patrimônio da Humanidade.

Cultural tourism and interpretation of heritage in the city of Diamantina-Minas Gerais/Brazil

Abstract: The city of Diamantina in Minas Gerais/Brazil had its architectural complex registered by the National Historical and Artistic Heritage Institute (IPHAN) in 1938 and in 1999 received the title of Cultural Heritage of Humanity by UNESCO. Evidently after this recognition new challenges arose from the relation between heritage and tourism in order to fulfill the objective of cultural tourism that is to promote the encounter between the tourist and the cultural heritage. The objective of this research was to address the importance of interpretation of heritage, identifying the existing strategies that facilitate the proximity of the tourist to the local heritage, taking as a case study the city of Diamantina. To this end, besides a bibliographical review on the relation between tourism and heritage, tourism demand research was carried out to identify the degree of tourist satisfaction in the monuments visited. The research is quantitative-descriptive with a qualitative approach.

Keywords: Tourism cultural; Interpretation of heritage; Diamantina/MG; Cultural heritage.

\section{Introdução}

Interpretação: uma palavra que nos faz viajar nos pensamentos quando é preciso olhar além do que está escrito ou exposto em algum lugar. Interpretar é uma forma bastante individual de captar mensagens que estão escondidas pelos símbolos. Ao considerarmos o campo patrimonial, a interpretação é uma ferramenta capaz de apresentar um mundo especial para as pessoas, por meio do planejamento aliado à sensibilidade, aproximando o visitante da história que é revelada pelo patrimônio preservado.

A interpretação patrimonial aliada ao turismo pode ser uma combinação promissora, tanto culturalmente quanto economicamente. O patrimônio não é apenas um produto da atividade turística exposto para os visitantes, mas um revelador de significados e de memórias que foram acumuladas com o passar do tempo. Através das técnicas adequadas a interpretação auxilia na qualidade do turismo cultural, agregando valor ao patrimônio e impulsionando a valorização e a preservação.

\footnotetext{
* Universidade de Coimbra (Portugal); E-mail: luciana-1515@hotmail.com

** Universidade de Coimbra (Portugal); E-mail: elcioneluciana@yahoo.com.br
} 
Podemos perceber essa importante relação nos destinos turísticos reconhecidos como patrimônio nacional e internacional, que cada vez mais vem se preocupando com a qualidade da atividade turística e buscando investir em equipamentos e ações que permitam uma fruição mais prazerosa dos visitantes pelos monumentos e cidades.

A interpretação do patrimônio se torna uma ferramenta importante e necessária para valorizar a história que o lugar possui, auxiliando na identificação do significado dos pequenos detalhes existentes, que costumam passam despercebidos diante dos olhares de seus visitantes. Possibilita vincular fato passados ao presente.

A cidade de Diamantina é detentora de um número significativo de monumentos históricos que são considerados um dos maiores motivadores para a visitação turística. Instrumentos de gestão são essenciais para equilibrar e harmonizar a atividade turística, e a interpretação patrimonial se apresenta como um desses instrumentos e uma grande aliada das cidades históricas com potencialidades turísticas (Pires, 2006).

.Apesar da riqueza cultural existente, e de ser Patrimônio Cultural da Humanidade, percebemos que em Diamantina, alguns dos recursos patrimoniais da cidade possuíam acervos limitados, falha na infraestrutura de atendimento, falta de sinalização interpretativa e poucas ações de comunicação que aproximasse o turista da história local. Elementos esses, que são importantes para o desenvolvimento do turismo cultural na cidade.

Portanto, esta pesquisa tem como objetivo estudar a importância da interpretação patrimonial como forma de valorização do patrimônio pelo turismo na cidade de Diamantina/MG, identificando ações de interpretação patrimonial, bem como os desafios e oportunidades existentes na cidade que permitam um melhor aproveitamento do patrimônio pelo turismo.

Para atingir o objetivo desta pesquisa foi realizada uma revisão bibliográfica em assuntos ligados aos temas de turismo cultural, patrimônio e técnicas de interpretação patrimonial. Daremos destaque aos conceitos e princípios da interpretação patrimonial estudada por Tilden, considerado o pai da interpretação do patrimônio (Bazán, 2014). Foi realizada ainda pesquisa de demanda turística com o intuito de compreender melhor a percepção dos turistas e visitantes aos elementos básicos para interpretação patrimonial em Diamantina. Esta pesquisa contou perguntas fechadas e abertas que buscaram compreender as expectativas, motivações, sugestões e críticas em relação ao monumento visitado. Foram aplicados entre 12/08/2016 a 28/09/2016, o total 154 questionários aos turistas, escolhidos de forma aleatória. Os questionários foram distribuídos da seguinte forma: 25 questionários em cada um dos seguintes monumentos (Casa de Chica, Instituto Casa da Glória, Museu do Diamante e Casa de Juscelino Kubistchek), onde havia um fluxo maior de visitação, e 18 questionários em cada desses monumentos (Igreja do Carmo, Bonfim e Rosário). A área da pesquisa limitou-se ao centro histórico de Diamantina, pelo conjunto de edificações históricas está mais restrito ao centro.

Trata-se de uma pesquisa quantitativa-descritiva que de acordo Dencker (1998) descreve fenômenos e estabelece relações entre variáveis. Utilizando de técnicas padronizadas para coleta de dados como os questionários que foram utilizados para pesquisa de campo. E também se enquadra como pesquisa qualitativa que controlada determinados elementos de concepções teóricas acerca do objeto de estudo, obtendo uma percepção aproximada da natureza dos fenômenos estudados (Dencker, 1998).

Os dados obtidos com a aplicação de questionários foram sistematizados e analisados por meio de tabelas e gráficos que serão apresentados nos próximos capítulos. Por meio desses dados foi possível propormos sugestões para melhoria nas ferramentas e técnicas da intepretação patrimonial como forma de contribuir com a qualidade da mensagem transmitida ao visitante.

\section{Turismo cultural e interpretação do patrimônio}

O patrimônio cultural representa os traços marcantes da identidade cultural de um povo e refletem o seu modo de vida e sua ligação com o passado construído coletivamente. Como afirma Choay (2006), o patrimônio cultural faz reviver no presente um passado, e mantém uma relação viva com a memória, com o tempo e o saber. Dependendo da forma como o patrimônio cultural é difundido (imagens, objetos, lugares, edificações, músicas, danças) constrói-se a memória histórica de um povo.

A atividade turística além de promover impulso econômico, pode contribuir ainda para valorização do patrimônio cultural. Ao conhecer novos lugares e outras culturas, vivenciando as experiências de um lugar, o turista pode adquirir novos conhecimentos, perceber seus elementos e símbolos singulares presente nos locais visitados. 
Sobre as relações existentes entre o turismo cultural a interpretação patrimonial, Costa (2009) evidencia a importância da comunicação interpretativa adequada para que o turismo possa contribuir com o papel de intermediador entre o visitante e o patrimônio cultural. Para as autoras, no contexto do turismo, por meio da apreciação, da vivência e da experimentação direta de bens do patrimônio cultural, seja material e imaterial, e da mediação da comunicação interpretativa, é possível que os visitantes participem de um "processo ativo de construção de conhecimento sobre o patrimônio e sobre seu contexto histórico" (Costa, 2009, pág. 190)

Lugares com potencial cultural instigam a curiosidade de outras pessoas em querer conhecer manifestações culturais que não fazem parte de sua realidade. E, portanto, o patrimônio cultural torna-se um dos motivadores de deslocamentos de turistas que buscam o conhecimento e novas experiências.

Segundo Tomazzoni (2009), o turismo cultural ainda tem na sua essência, a virtude de fortalecer os valores de caráter cultural, representando e promovendo relações de aprendizagem entre as pessoas. Alinhado a interpretação patrimonial, o turismo pode também contribuir não somente para o desenvolvimento de uma localidade economicamente, mas pode permitir também um intercâmbio de experiências culturais e de conhecimento que contribuem para que as pessoas, tanto turistas como comunidade receptora, se sintam pertencentes a uma história e uma identidade.

Antes de falarmos sobre a importância da interpretação patrimonial para o turismo e para reconhecimento da identidade de um povo, torna-se necessário compreender melhor a relação entre o turismo e patrimônio.

Para Camargo (2004) tanto o turismo como patrimônio são característicos das sociedades industriais, que são elementos localizados e datados dos fins do século XVIII. Segundo o autor, o conceito do patrimônio surgiu juntamente com a Revolução Francesa e foi definido enquanto "patrimônio" em detrimento de razões práticas e ajustado à ideologia do Estado Nacional, para evitar o vandalismo que emergia na época e, portanto, as discussões ideológicas que envolviam a preservação de elementos representativos, contribuíram, mais tarde, para um maior empenho na preservação e valorização de bens culturais e naturais, não somente na França, mais em outros países. A partir daí, o turismo surge nessa relação com o patrimônio como atividade que acrescenta valor econômico ao bem e também contribui para a proteção do mesmo, por meio de uma maior aproximação da comunidade com a cultura e seu patrimônio preservado. Sendo a interpretação patrimonial uma aliada na promoção do sentimento de pertencimento da sociedade com o seu patrimônio cultural.

Educação e interpretação patrimonial são ferramentas voltadas para o patrimônio cultural que se apresentam como uma fonte importante de conhecimento individual e coletivo. No entanto há uma distinção fundamental entre elas.

De acordo com Tilden (1957), a interpretação patrimonial é uma arte que combina várias técnicas para explicar os temas apresentados (científico, natural, histórico, cultural, etc.), e também se apresenta como ciência, onde a informação adequada é primordial para instigar os sentidos dos visitantes.

Aprendemos a fazer uma leitura da nossa realidade cotidiana, quando consideramos ações que contribuam para uma maior reflexão sobre quem somos e qual é o nosso papel na sociedade. Nesse sentido, a interpretação também pode atuar como mediadora das comunidades locais para resgatar sua história e sua cultura por intermédio da educação patrimonial que é um alicerce para o desenvolvimento das técnicas de interpretação do patrimônio (Farias, 2002).

Cardozo e Melo (2015) corroboram com tal pensamento mencionando que a atividade turística, ao colocar frente a frente os turistas e a herança cultural na forma de patrimônio, propicia o intercâmbio cultural. Ao realizar uma ação educativa para o patrimônio, o que se faz é planejar metodologias e conteúdo para fazer com que aquele que ainda não conhece o patrimônio, venha se apropriar destas formas humanas de expressão, propagando conteúdos por um viés cultural, social e político, buscando a prática educacional em um patrimônio (Cardozo \& Melo, 2015).

Cidades que possuem atributos culturais como potencial turístico, são lugares que se apresentam como um museu a céu aberto e são capazes de transportar o visitante para tempos remotos proporcionando experiências diferentes do qual está habituado. A interpretação do patrimônio se torna uma ferramenta importante e necessária para valorizar a história que o lugar possui, auxiliando na identificação do significado dos pequenos detalhes existentes, que costumam passar despercebidos diante dos olhares de seus visitantes.

Considerados os fundamentos teóricos e metodológicos da interpretação do patrimônio, como é conhecida atualmente, Bazán (2014), salienta que a essência da interpretação é revelar aos visitantes a beleza, maravilha, inspiração e significado, de forma que as experiências adquiridas ultrapassem a simples intenção de transmissão de informações. 
Segundo Beorlegui (2016), temos a capacidade de visualizar diferentes situações, experimentar sonhos, desejos e ideias, gerando novas alternativas para atuar ante as circunstâncias, criando novos pensamentos e novas aprendizagens. Este autor ressalta ainda que quando visitamos algum lugar carregado de memória nos transportamos para outra dimensão e assim estimula nossa imaginação e curiosidade por coisas que nos rodeia e nos permite buscar respostas, dando lugar a formação de novos conhecimentos. Entretanto, ferramentas adequadas de transmissão desses conhecimentos se tornam importantes.

Nesse aspecto é interessante citar Costa (2009), que argumenta que as interpretações são formas de intervenções antecipadas, para preparar o patrimônio à prática do turismo cultural. Um bom planejamento interpretativo facilita a identificação de situações em que os turistas teriam possíveis dificuldades de compreensão, por exemplo: visitantes com necessidades especiais que necessitam de ações como; acessibilidade, placas em braile, ou no caso das crianças, e, portanto, as informações devem ser acessíveis e disponibilizadas adequadamente.

No próximo tópico, discutiremos como a interpretação pode contribuir para uma melhor experiência turística. Apresentaremos ainda os resultados obtidos da pesquisa de demanda e que contribuíram para compreender melhor a importância das ferramentas de interpretação patrimonial para a valorização do patrimônio e sua preservação, tendo como estudo de caso, a cidade de Diamantina em Minas Gerais/ Brasil que foi reconhecida como Patrimônio Cultural da Humanidade em 1999 pela (UNESCO).

\section{Estudo da satisfação do turista nos monumentos: possibilidades de ações de interpretação do patrimônio em diamantina}

A cidade de Diamantina está localizada na mesorregião no Alto do Jequitinhonha, nordeste de Minas Gerais. Com quase três séculos de fundação, surgiu em decorrência da descoberta de diamantes e por este motivo atraiu a atenção mundial por ser uma das três principais áreas que produziram diamantes no mundo. Segundo o Instituto do Patrimônio Histórico e Artístico Nacional (1999) o fato de se destacar pela exploração do diamante e não do ouro, fez com que Diamantina fosse diferenciada do restante do Brasil, tendo outro regime político e administrativo, e que influenciou sua cultura, sua arquitetura e traçado urbano.

O conjunto arquitetônico da cidade e as tradições preservadas despertaram interesse do Serviço do Patrimônio Histórico e Artístico Nacional (SPHAN) que em 16 de maio de 1938 realizou o seu tombamento, reconhecendo a importância que a cidade possuía para a formação da história do Brasil no período colonial.

Em 1999, a cidade de Diamantina foi enaltecida e colocada em um patamar considerável em nível de importância no âmbito do turismo com o título de patrimônio cultural da humanidade pela Organização das Nações Unidas para a educação, a ciência e a cultura (UNESCO). Evidentemente um título tão significativo carrega consigo uma grande responsabilidade, e assim surgem novos desafios advindos da relação entre patrimônio e turismo no sentido de adequar a cidade para receber turistas e oferecer uma fruição turística de qualidade, por meio das ações e técnicas para interpretação patrimonial.

Com o intuito de compreender melhor a percepção e o nível de satisfação dos turistas em relação aos elementos básicos para interpretação patrimonial em Diamantina, foi realizada uma pesquisa de demanda aplicadas nos principais monumentos históricos da cidade e que se encontravam abertos à visitação turística: Casa de Chica, Casa da Glória, Museu do Diamante, Casa de Juscelino Kubistchek, Igreja do Carmo, Igreja do Bonfim e Igreja do Rosário. A amostra utilizada foi por conveniência, que segundo Gil (1999, p.104) "é o processo em que o pesquisador seleciona os elementos a que tem acesso, admitindo que estes possam de alguma forma, representar o universo". Após analise dos dados obtidos com a aplicação do questionário obtivemos informações que contribuíram para a sugestão de melhorias das ferramentas de interpretação patrimonial nos monumento visitado, bem como conhecer melhor o perfil do público que visitava Diamantina.

De acordo com a pesquisa $37 \%$ dos turistas possuía idade entre 41 e 50 anos, seguido de $25 \%$ que possuíam a idade entre 31 a 40 anos. Podemos supor que o público que mais frequenta Diamantina seja pessoas com mais experiência, que busca por novidades e conhecimento. Ao serem indagados sobre o nível de escolaridade, $88 \%$ dos entrevistados disseram possuir o superior completo. Portanto, percebemos que a maioria dos entrevistados possui um nível alto de instrução, sendo um público mais exigente quanto às informações disponibilizadas. 
Quando questionados se sabiam que Diamantina era Patrimônio Cultural da Humanidade, cerca de 98\% dos pesquisados disseram que "Sim". O que indica que Diamantina tem sido divulgada adequadamente nos meios de comunicação, e que o título de patrimônio pode contribuir para a promoção dos deslocamentos à cidade. O que sinaliza o quanto é necessário uma melhor otimização dos recursos patrimoniais.

Quando questionados sobre o que os motivou a vir conhecer Diamantina, cerca de 34\% dos entrevistados apontaram a cultura como fator motivacional, seguido por $21 \%$ dos entrevistados que disseram vir visitar parentes e amigos, $19 \%$ apontaram a arquitetura como motivação, $10 \%$ responderam que vieram motivados pelos eventos que aconteceriam na cidade. Houve um equilíbrio entre a motivação da cidade ser "patrimônio da humanidade" e a motivação "Trabalho", no que somaram 10\%. Percebe-se que a cultura novamente aparece como um fator motivacional da maioria dos entrevistados, que juntamente com arquitetura e personagens, apresenta um dado significativo de $56 \%$ dos entrevistados. $\mathrm{E}$, portanto, reforça mais uma vez a necessidade de investir melhor na acessibilidade ao monumento e na qualidade das informações.

Sobre outros monumentos históricos visitados, a pesquisa revelou que 99 pessoas já haviam visitado a Catedral de Diamantina, que é um monumento de destaque e bem localizado, seguido por 78 respondentes que apontaram visita ao Museu do Diamante. O Mercado Velho obteve 75 dos respondentes, 55 pessoas disseram que havia visitado a Casa de Chica da Silva; 41 pessoas havia visitado a Casa JK e o Instituto Casa da Glória foi visitado por 32 turistas (GRÁFICO 01).

\section{Gráfico 01: Turistas que visitaram outros monumentos históricos}

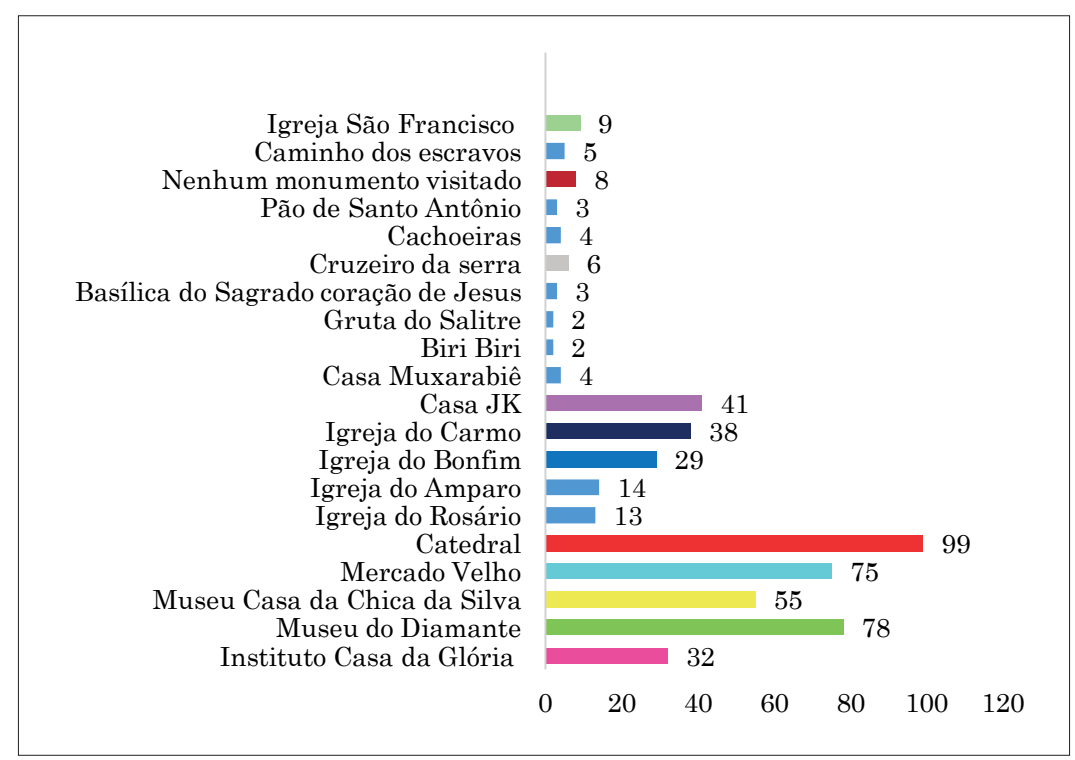

Fonte: Elaboração da autora baseado nos dados obtidos em 2016

Umas das ações essenciais e básicas em uma cidade que possui o turismo cultural como principal motivação, é o acesso ao monumento. $\mathrm{O}$ acesso é importante para que o turista volte satisfeito com o que visitou. Entretanto, apesar de esforços entre as instituições como Secretaria de Cultura, Turismo e Patrimônio, o empresariado local, Conselho Municipal de Turismo, Universidade Federal dos Vales do Jequitinhonha e Mucurí, MITRA e Irmandades para abertura de mais monumentos religiosos de forma regular, isso ainda se apresenta como um desafio em Diamantina. Além da dificuldade em horários de abertura, muitos monumentos não possuem o acervo que o bem cultural necessita para se trabalhar a interpretação patrimonial, conforme autores como Tilden sugere, como por exemplo ir além de informar, estimulando outros sentidos.

De acordo com a tabela 01, podemos perceber o nível de satisfação do turista em relação à infraestrutura na Casa da Glória. A maioria das ações interpretativas teve avaliação 'ótimo’ e ‘bom' como os mais citados. 
Tabela 1: Avaliação da infraestrutura no Museu Casa da Glória

\begin{tabular}{|l|c|c|c|c|c|c|}
\hline \multicolumn{1}{|c|}{ Infraestrutura } & Ótimo & Bom & Regular & Ruim & Péssimo & Não possui \\
\hline Acolhida e receptividade & 16 & 9 & & & & \\
\hline Qualidade no atendimento aos visitantes & 14 & 11 & & & & \\
\hline Sinalização turística indicativa & 12 & 6 & 5 & 2 & & \\
\hline Sinalização turística interpretativa & 15 & 10 & & & & \\
\hline $\begin{array}{l}\text { Acesso às informações turísticas sobre o } \\
\text { monumento }\end{array}$ & 14 & 11 & & & & \\
\hline Segurança & 17 & 8 & & & & \\
\hline Limpeza & 17 & 8 & & & & \\
\hline Acessibilidade & 14 & 8 & 3 & & & \\
\hline Conservação dos monumentos & 16 & 9 & & & & \\
\hline Horário de funcionamento do monumento & 15 & 10 & & & & \\
\hline $\begin{array}{l}\text { Informações oferecidas sobre o bem cultural } \\
\text { (são suficientes e atraentes, aumentaram a } \\
\text { curiosidade.) }\end{array}$ & 15 & 10 & & & & \\
\hline Informações sobre o monumento (impresso) & & & & & & \\
\hline $\begin{array}{l}\text { Sobre o acervo artístico, histórico e cultural } \\
\text { do monumento }\end{array}$ & 14 & 11 & & & & \\
\hline $\begin{array}{l}\text { Recursos utilizados nas informações } \\
\text { (multimídia, toten interativo, sinalização) }\end{array}$ & 16 & 9 & & & & \\
\hline $\begin{array}{l}\text { Satisfação e expectativas com as } \\
\text { informações no monumento }\end{array}$ & 14 & 11 & & & & \\
\hline
\end{tabular}

A insatisfação desses visitantes volta-se à falta sinalização indicativa no monumento. Os turistas elogiaram a visita e a acolhida no lugar. Ao iniciar a visita é possível assistir um vídeo de apresentação da Casa da Glória, o que é importante para se inteirar do que o lugar representa e a sua história. Entretanto, alguns visitantes sugeriram a presença de um guia local para mais informações, apesar do monumento contar com o auxílio da placa autoguiada. Alguns dos turistas gostaram do acervo e outros já sentiram falta de um acervo mais completo, pois segundo eles, o museu tem poucas informações sobre a Casa da Glória e mais informação sobre assuntos ligado à geologia.

Em relação à casa de Juscelino Kubistchek, a maioria dos entrevistados apontou um nível considerável de satisfação, conforme Tabela 02. 
Tabela 2: Avaliação da infraestrutura na casa de Juscelino Kubistchek

\begin{tabular}{|c|c|c|c|c|c|c|}
\hline Infraestrutura & Ótimo & Bom & Regular & Ruim & Péssimo & Não possui \\
\hline Acolhida e receptividade & 17 & 8 & & & & \\
\hline Qualidade no atendimento aos visitantes & 12 & 12 & 1 & & & \\
\hline Sinalização turística indicativa & 12 & 13 & & & & \\
\hline Sinalização turística interpretativa & 19 & 6 & & & & \\
\hline $\begin{array}{l}\text { Acesso às informações turísticas sobre o } \\
\text { monumento }\end{array}$ & 15 & 10 & & & & \\
\hline Segurança & 21 & 4 & & & & \\
\hline Limpeza & 20 & 5 & & & & \\
\hline Acessibilidade & 11 & 7 & 7 & & & \\
\hline Conservação dos monumentos & 23 & 2 & & & & \\
\hline Horário de funcionamento do monumento & 13 & 5 & 7 & & & \\
\hline $\begin{array}{l}\text { Informações oferecidas sobre o bem } \\
\text { cultural (são suficientes e atraentes, } \\
\text { aumentaram a curiosidade.) }\end{array}$ & 19 & 6 & & & & \\
\hline $\begin{array}{l}\text { Informações disponibilizadas sobre o } \\
\text { monumento (impresso) }\end{array}$ & 14 & 11 & & & & \\
\hline $\begin{array}{l}\text { Sobre o acervo artístico, histórico e } \\
\text { cultural do monumento }\end{array}$ & 21 & 4 & & & & \\
\hline $\begin{array}{l}\text { Recursos utilizados nas informações } \\
\text { (multimídia, toten interativo, sinalização, } \\
\text { etc) }\end{array}$ & 17 & 7 & 1 & & & \\
\hline $\begin{array}{l}\text { Satisfação e expectativas com as } \\
\text { informações no monumento }\end{array}$ & 18 & 7 & & & & \\
\hline
\end{tabular}

Turistas mais exigentes sentiram a necessidade de ter um guia para acompanhar a visita. O museu possui funcionários para recepcionar os visitantes, mas, os mesmos não desempenham a função de guiar a visita, portanto o visitante fica livre para explorar o museu.

Dos entrevistados, apenas 07 , não ficaram satisfeitos com o horário de abertura, pois gostariam que o local abrisse no domingo à tarde. E em relação à acessibilidade houve associação com a localização do museu, que fica em uma subida bastante íngreme, e segundo os entrevistados dificultam o acesso à casa.

Os recursos utilizados nas informações foram bem avaliados pelos turistas, entretanto 08 dos entrevistados mencionaram a necessidade de interação com o visitante, como áudios, documentários e mencionaram que o museu tinha poucas informações em língua estrangeira. A Casa de JK obteve boa avaliação, foi elogiada a receptividade, o acervo, hospitalidade. Além disso, os visitantes citaram o bar e café localizado no porão do museu, como um lugar aconchegante, onde se podem tomar um café e comprar livros, CD, ouvir música.

A casa Chica da Silva foi o monumento com maior número de críticas e insatisfação do turista, 19 dos entrevistados apontaram como "bom" a receptividade, somente 01 como "ótimo" e 05 pessoas como regular. A receptividade no museu é simples, tem uma pessoa para receber e a única informação que o turista recebe é que precisa apenas assinar um livro, mas não é sempre que tem pessoas para recepcionar. Essas 05 pessoas que responderam como regular, foram as que encontraram a recepção sem ninguém para recebê-las. 
Tabela 3: Avaliação da infraestrutura na Casa de Chica da Silva

\begin{tabular}{|c|c|c|c|c|c|c|}
\hline Infraestrutura & Ótimo & Bom & Regular & Ruim & Péssimo & Não possui \\
\hline Acolhida e receptividade & 1 & 19 & 5 & & & \\
\hline Qualidade no atendimento aos visitantes & & 11 & 12 & 2 & & \\
\hline Sinalização turística indicativa & & 6 & 13 & 6 & & \\
\hline Sinalização turística interpretativa & & 5 & 16 & 4 & & \\
\hline $\begin{array}{l}\text { Acesso às informações turísticas sobre o } \\
\text { monumento }\end{array}$ & & 3 & 20 & 2 & & \\
\hline Segurança & 18 & 7 & & & & \\
\hline Limpeza & 22 & 3 & & & & \\
\hline Acessibilidade & 10 & 14 & 1 & & & \\
\hline Conservação dos monumentos & 22 & 3 & & & & \\
\hline Horário de funcionamento do monumento & & 3 & 7 & 12 & 3 & \\
\hline $\begin{array}{l}\text { Informações oferecidas sobre o bem cultural } \\
\text { (são suficientes e atraentes, aumentaram a } \\
\text { curiosidade.) }\end{array}$ & & 2 & 18 & 5 & & \\
\hline Informações sobre o monumento (impresso) & & & & & & 25 \\
\hline Sobre o acervo artístico, histórico e cultural & 5 & 5 & 11 & 4 & & \\
\hline $\begin{array}{l}\text { Recursos utilizados nas informações } \\
\text { (multimídia, toten interativo, sinalização, } \\
\text { etc) }\end{array}$ & & 5 & 13 & 5 & 2 & \\
\hline $\begin{array}{l}\text { Satisfação e expectativas com as } \\
\text { informações }\end{array}$ & 2 & 2 & 13 & 8 & & \\
\hline
\end{tabular}

A qualidade no atendimento também não agradou, pois a maioria dos visitantes sentiu falta de um guia para acompanhá-los durante a visita, já que a casa tem poucas informações. Em relação à sinalização turística indicativa, a maioria dos visitantes avaliou de forma insatisfatória, pela falta de sinalização na cidade e também dentro do monumento. A sinalização interpretativa não foi bem avaliada. A casa não apresenta um acervo e nem recursos que proporcionem uma interatividade com o visitante. Somente 06 pessoas avaliaram como "bom", pois havia uma exposição sobre Chica da Silva de uma artista local. Percebe-se o quanto ações simples já podem mudar a percepção do turista.

Outros quesitos tiveram avaliação baixa, como as informações oferecidas sobre o bem cultural e sobre o acervo artístico, que se apresentam bastante restrito. As informações disponibilizadas sobre o monumento (impresso) é um recurso que não é disponibilizado pelo monumento. Sobre o acervo artístico, histórico e cultural do monumento segundo os visitantes, deveria ter um acervo mais completo, mas a beleza da arquitetura chamou atenção dos visitantes.

Já no Museu do Diamante, podemos perceber, de acordo com a tabela 04, que este monumento foi bem avaliado pela maioria dos turistas. Houve uma insatisfação maior dos visitantes em relação à sinalização indicativa, já que o museu passa despercebido diante dos olhares das pessoas, pela falta de uma sinalização que chame a atenção do público. 
Tabela 4: Avaliação da Infraestrutura no Museu do Diamante

\begin{tabular}{|l|c|c|c|c|c|c|}
\hline \multicolumn{1}{|c|}{ Infraestrutura } & Ótimo & Bom & Regular & Ruim & Péssimo & Não possui \\
\hline Acolhida e receptividade & 6 & 18 & 1 & & & \\
\hline Qualidade no atendimento aos visitantes & 6 & 17 & 2 & & & \\
\hline Sinalização turística indicativa & 4 & 4 & 5 & 12 & & \\
\hline Sinalização turística interpretativa & 5 & 16 & 4 & & & \\
\hline $\begin{array}{l}\text { Acesso às informações turísticas sobre o } \\
\text { monumento }\end{array}$ & 5 & 13 & 7 & & & \\
\hline Segurança & 20 & 5 & & & & \\
\hline Limpeza & 20 & 5 & & & & \\
\hline Acessibilidade & 4 & 8 & 13 & & & \\
\hline Conservação dos monumentos & 22 & 3 & & & & \\
\hline Horário de funcionamento do monumento & 16 & 9 & & & & \\
\hline $\begin{array}{l}\text { Informações oferecidas sobre o bem cultural } \\
\text { (são sucientes e atraentes, aumentaram a } \\
\text { curiosidade.) }\end{array}$ & 8 & 14 & 3 & & & \\
\hline Informações sobre o monumento (impresso) & & & & & & \\
\hline Sobre o acervo artístico, histórico e cultural & 12 & 8 & 5 & & & \\
\hline $\begin{array}{l}\text { Recursos utilizados nas informações } \\
\text { (multimídia, toten interativo, sinalização, } \\
\text { etc) }\end{array}$ & 13 & 8 & 4 & & & \\
\hline $\begin{array}{l}\text { Satisfação e expectativas com as } \\
\text { informações no monumento }\end{array}$ & 5 & 17 & 3 & & & \\
\hline
\end{tabular}

A sinalização turística interpretativa foi bem avaliada pelos visitantes, o museu tem placas explicativas na maioria das peças. $\mathrm{O}$ acesso às informações turísticas sobre o monumento também foi bem avaliado. A segurança e a limpeza tiveram uma excelente avaliação. A acessibilidade foi um quesito que teve críticas pela falta de rampas de acesso, apesar de ser um problema que abrange todo centro histórico. Sobre as informações oferecidas concernentes ao bem cultural, a maioria dos visitantes avaliou com 'bom', mas alguns turistas sentiram falta de mais informações sobre a atividade garimpeira na cidade, pois o nome do museu cria essa expectativa. O museu não disponibiliza informações impressas para os visitantes.

A maioria avaliou como 'bom' o acervo artístico, histórico e cultural do monumento, mas houve críticas em relação ao museu ter pouco acervo sobre a mineração na cidade. Os recursos utilizados nas informações para aproximar o visitante à história foi avaliado como 'ótimo' por 13 entrevistados. $\mathrm{O}$ museu possui guias para acompanhar a visita e isso auxilia o visitante a compreender melhor a história da cidade. Mas alguns dos turistas disseram sentir falta de mais interatividade com o visitante e da utilização de recursos mais modernos.

Em relação aos monumentos religiosos, pudemos fazer uma observação geral de todas as variáveis relacionadas à infraestrutura, acervo, atendimento. No caso da Igreja de Nossa Senhora do Carmo, podemos notar, tabela 05 , uma insatisfação dos visitantes. 
Tabela 5: Avaliação infraestrutura na igreja do Carmo

\begin{tabular}{|l|c|c|c|c|c|c|}
\hline \multicolumn{1}{|c|}{ Infraestrutura } & Ótimo & Bom & Regular & Ruim & Péssimo & Não possui \\
\hline Acolhida e receptividade & 1 & 3 & 11 & 3 & & \\
\hline Qualidade no atendimento aos visitantes & 1 & 3 & 9 & 5 & & \\
\hline Sinalização turística indicativa & 1 & 4 & 8 & 5 & & \\
\hline Sinalização turística interpretativa & 1 & 4 & 10 & 3 & & \\
\hline $\begin{array}{l}\text { Acesso às informações turísticas sobre o } \\
\text { monumento }\end{array}$ & 1 & 3 & 10 & 4 & & \\
\hline Segurança & 2 & 15 & 1 & & & \\
\hline Limpeza & 1 & 16 & 1 & & & \\
\hline Acessibilidade & 1 & 13 & 4 & & & \\
\hline Conservação dos monumentos & 1 & 15 & 2 & & & \\
\hline Horário de funcionamento do monumento & 1 & 7 & 7 & 3 & & \\
\hline $\begin{array}{l}\text { Informações oferecidas sobre o bem cultural } \\
\text { (são suficientes e atraentes, aumentaram a } \\
\text { curiosidade.) }\end{array}$ & 1 & 4 & 11 & 2 & & \\
\hline Informações sobre o monumento (impresso) & & & & & & \\
\hline Sobre o acervo artístico, histórico e cultural & 11 & 7 & & & & \\
\hline $\begin{array}{l}\text { Recursos utilizados nas informações } \\
\text { (multimídia, toten interativo, sinalização, etc) }\end{array}$ & 1 & 3 & 11 & 3 & & \\
\hline $\begin{array}{l}\text { Satisfação e expectativas com as } \\
\text { informaços no monumento }\end{array}$ & 1 & 5 & 11 & 1 & \\
\hline
\end{tabular}

A acolhida e receptividade no monumento foram avaliadas como 'regular' por 11 dos entrevistados. A igreja não possui guias para atendimento. Os atendentes da recepção se dividem em receber os visitantes e cuidar da igreja, como na limpeza, por exemplo.

A sinalização turística indicativa foi avaliada de forma insatisfatória pelos turistas, 09 pessoas disseram que era regular e 05 como "ruim". O turista não percebe que a Igreja se encontra aberta à visitação e também pela falta de sinalização adequada que chame a atenção do público. A sinalização turística interpretativa obteve avaliação da maioria como 'regular' por 10 pessoas e ruim por 03. No monumento há poucas informações sobre a igreja e o acervo artístico. A segurança, limpeza e conservação do monumento foram bem avaliados pelos turistas que opinaram como 'bom'.

As informações oferecidas sobre o bem cultural não foram suficientes de acordo com os turistas, 11 pessoas opinaram com "regular" e 03 como "ruim". Quando questionadas sobre o acervo artístico, histórico do monumento, 11 pessoas avaliaram como 'ótimo'. Os recursos utilizados nas informações foram avaliados de forma insatisfatória pela maioria dos pesquisados, 11 pessoas avaliaram com regular e 03 como "ruim". No monumento não existe interatividade com o visitante e nem a presença de um guia para auxiliar a visita. Podemos perceber uma avaliação muito baixa do visitante em relação à visita.

Sobre a Igreja de Nosso Senhor do Bomfim, podemos perceber pela tabela 06, que os entrevistados de uma forma geral, avaliaram como 'bom' e 'ótimo' a infraestrutura da igreja. 
Tabela 6: Avaliação da infraestrutura na Igreja de N.Sr do Bonfim

\begin{tabular}{|c|c|c|c|c|c|c|}
\hline Infraestrutura & Ótimo & Bom & Regular & Ruim & Péssimo & Não possui \\
\hline Acolhida e receptividade & 18 & & & & & \\
\hline Qualidade no atendimento aos visitantes & 18 & & & & & \\
\hline Sinalização turística indicativa & 7 & 1 & 9 & 1 & & \\
\hline Sinalização turística interpretativa & 7 & 4 & 7 & & & \\
\hline $\begin{array}{l}\text { Acesso às informações turísticas sobre o } \\
\text { monumento }\end{array}$ & 5 & 6 & 7 & & & \\
\hline Segurança & 13 & 5 & & & & \\
\hline Limpeza & 14 & 4 & & & & \\
\hline Acessibilidade & 12 & 6 & & & & \\
\hline Conservação dos monumentos & 13 & 5 & & & & \\
\hline Horário de funcionamento do monumento & 11 & 5 & 2 & & & \\
\hline $\begin{array}{l}\text { Informações oferecidas sobre o bem cultural } \\
\text { (são suficientes e atraentes, aumentaram a } \\
\text { curiosidade.) }\end{array}$ & 7 & 11 & & & & \\
\hline Informações sobre o monumento (impresso) & & & & & & 18 \\
\hline $\begin{array}{l}\text { Sobre o acervo artístico, histórico do } \\
\text { monumento }\end{array}$ & 12 & 6 & & & & \\
\hline $\begin{array}{l}\text { Recursos utilizados nas informações } \\
\text { (multimídia, toten interativo, sinalização, etc) }\end{array}$ & 11 & 7 & & & & \\
\hline $\begin{array}{l}\text { Satisfação e expectativas com as } \\
\text { informações no monumento }\end{array}$ & 5 & 13 & & & & \\
\hline
\end{tabular}

Houve uma insatisfação de 09 pessoas com a sinalização indicativa. A sinalização interpretativa e o acesso às informações turísticas, tiveram avaliação 'regular' de acordo com 07 pessoas, a igreja possui apenas uma placa de acrílico na parte externa, onde conta um pouco sobre a história da igreja. Podemos perceber que a maioria dos visitantes avaliou positivamente a igreja. Esta Igreja possui guias de turismo capacitadas que recepcionam e auxiliam o visitante, e também contam com o auxílio de bolsistas de cursos distintos da Universidade Federal dos Vales do Jequitinhonha e Mucuri (UFVJM). Através de um projeto da Pró-Reitoria de Assuntos Comunitários e Estudantis (PROACE), os bolsistas são responsáveis por auxiliar o turista no monumento. Porém, segundo os guias que trabalham no local, nem todos os bolsistas têm interesse na função, e isso é um lado negativo do projeto. Pois, se não há interesse, o objetivo da interpretação patrimonial que é de informar e instigar a curiosidade do turista, não será desenvolvido de forma adequada. Na igreja há pouca interatividade com o visitante e poucas informações sobre o monumento expostas.

Em relação à igreja do Rosário, a maioria dos entrevistados apontou um nível considerável de satisfação. Porém houve avaliações baixas com opinião de '13' pessoas, principalmente em relação à sinalização indicativa. 
Tabela 7: Avaliação da infraestrutura na igreja do Rosário

\begin{tabular}{|l|c|c|c|c|c|c|}
\hline \multicolumn{1}{|c|}{ Infraestrutura } & Ótimo & Bom & Regular & Ruim & Péssimo & Não possui \\
\hline Acolhida e receptividade & 15 & 3 & & & & \\
\hline Qualidade no atendimento aos visitantes & 16 & 2 & & & & \\
\hline Sinalização turística indicativa & 2 & 1 & 13 & 2 & & \\
\hline Sinalização turística interpretativa & 3 & 4 & 11 & & & \\
\hline $\begin{array}{l}\text { Acesso às informações turísticas sobre o } \\
\text { monumento }\end{array}$ & 17 & 1 & & & & \\
\hline Segurança & 17 & 1 & & & & \\
\hline Limpeza & 16 & 2 & & & & \\
\hline Acessibilidade & 4 & 9 & 5 & & & \\
\hline Conservação dos monumentos & 16 & 2 & & & & \\
\hline Horário de funcionamento do monumento & 14 & 3 & 1 & & & \\
\hline $\begin{array}{l}\text { Informações oferecidas sobre o bem cultural } \\
\text { (são suficientes e atraentes, aumentaram a } \\
\text { curiosidade.) }\end{array}$ & 14 & 3 & 1 & & & \\
\hline $\begin{array}{l}\text { Informações disponibilizadas sobre o } \\
\text { monumento (impresso) }\end{array}$ & & & & & & \\
\hline $\begin{array}{l}\text { Sobre o acervo artístico, histórico e cultural } \\
\text { do monumento }\end{array}$ & 8 & 10 & & & & \\
\hline $\begin{array}{l}\text { Recursos utilizados nas informações } \\
\text { (multimídia, toten interativo, sinalização, } \\
\text { etc) }\end{array}$ & 12 & 6 & & & & \\
\hline $\begin{array}{l}\text { Satisfação e expectativas com as informações } \\
\text { no monumento }\end{array}$ & 13 & 5 & & & \\
\hline
\end{tabular}

Mais uma vez aparecem os mesmos desafios apresentados na Igreja do Carmo e Bonfim. A porta principal da igreja não fica aberta, e como a igreja do Rosário se encontra localizada mais distante das outras, dificulta que o turista perceba que a Igreja esteja aberta a visitação. A sinalização interpretativa e o acesso às informações turísticas tiveram avaliação 'regular' de acordo com 11 pessoas. Um número significativo, o que indica que há uma carência do visitante em relação às informações expostas. Podemos perceber que a maioria dos visitantes avaliou de forma satisfatória da igreja. O monumento possui guias capacitadas que recepcionam e auxiliam o visitante, e também os bolsistas da UFVJM, assim como na Igreja do Bonfim. Na igreja há pouca interatividade com o visitante em termos de recursos que aproxime o turista com a história do lugar, e poucas informações expostas.

Podemos perceber por estes dados analisados, a necessidade de ações que possam se apresentar como possibilidades para interpretação, valorização do monumento e melhor aproveitamento do patrimônio pelo turismo. Tomando como base essas avaliações e observações realizadas, propomos nesta pesquisa algumas possibilidades de melhorias nas ferramentas e técnicas de interpretação do patrimônio para os monumentos históricos de Diamantina. Julga-se necessário salientar que, não se pretende aqui propor um plano interpretativo para Diamantina, mas, sim propor algumas estratégias que seriam viáveis para valorizar e otimizar as visitas nos monumentos históricos.

Uma cidade que é alicerçada na história como é o caso de Diamantina, a interpretação seria uma ferramenta bastante viável para uma melhor otimização dos recursos patrimoniais. E iria contemplar tanto turistas que poderiam fazer uma melhor leitura da cidade e também os moradores locais despertando o interesse e o sentimento de pertencimento.

Porém, é necessário um planejamento que oriente as ações futuras contemplando o bem-estar de todos, fazendo com que determinado local esteja apto para receber turistas, propiciando-lhes experiências de qualidade. É importante que esse planejamento seja direcionado para ações dentro de um contexto histórico. 
Nesse aspecto é imprescindível citar os seis princípios básicos que norteiam o esquema interpretativo de (TILDEN, 1957) em destacar que devemos:

1) Sempre focalizar os sentidos dos visitantes, de forma a estabelecer a concientização pessoal sobre determinadas caracteristicas do ambiente.

2) Revelar sentidos com base nas informaçõese e não apenas informar

3) Utilizar muitas artes visuais e de animação, seja o material apresentado científico histórico ou arquitetônico.

4) Não apenas instruir, mas provocar, estimulando a curiosidade do visitante, encorajando a exploração mais aprofundada do que está sendo interpretado.

5) Apresentar a história completa, em vez de parte desta; dirigir-se a pessoa inteira.

6) Ser acessível a um público o mais amplo possível, levando em consideração necessidades especiais.

Tendo em vista a evolução da interpretação desde a época de Tilden (1957) em que esses princípios foram criados, GOODEY e MURTA (2002) corroboram com o autor e ainda acrescentam os seguintes princípios interpretativos:

1) Iniciar a interpretação em parceria com a comunidade, estimulando a troca de conhecimentos e recursos.

2) Adotar uma abordagem abrangente, ligando os temas do passado, do presente e do futuro, realçando a dimensão socioeconômica, ao lado das dimensões histórica, ecológica e arquitetônica.

3) Não tentar vender uma verdade universal, mas destacar a diversidade e a pluralidade culturais. Sua interpretação deve fomentar a aceitação e a tolerância como valores democráticos.

4) Levar sempre em consideração o atendimento ao cliente, indicando ou provendo instalações básicas, como sanitários, segurança, pontos de descanso e estacionamento, elementos essenciais a uma experiência prazerosa do lugar (GOODEY e MURTA, 2002, pág. 18)

São princípios que devem ser levados em consideração quando se pensa em implantar um plano interpretativo em um lugar. De acordo com Brochu e Merriman (2012), os objetivos da interpretação são vários, podem incluir o desenvolvimento de conexões emocionais e intelectuais ente os visitantes e os visitantes e os significados inerentes ao recurso patrimonial. Outro autor que ressalta a importância da interpretação, mas desta vez, como importante ferramenta de gestão turística é, Morales (2012). Segundo este autor, a interpretação patrimonial pode contribuir com as dinâmicas de rentabilidade e se tornar um importante instrumento capaz de apoiar a criação de políticas de intervenção e uso social do bem patrimonial. Já ao considerar o aproveitamento dos recursos patrimoniais pelo turismo, Téllez e García (2016) ressaltam que as técnicas e ferramentas da interpretação do patrimônio podem ainda, permitir que o território se torne mais competitivo e desenvolva melhores ações de promoção e exploração pelo turismo.

$\mathrm{Na}$ tabela 8, contém informações sobre os monumentos históricos que foram alvos da pesquisa. E com base nas informações obtidas com a pesquisa propomos algumas estratégias para uma melhor comunicação e aproximação entre o visitante e a história do local, através das técnicas de interpretação do patrimônio. 


\section{Tabela 8: Possibilidades interpretação patrimonial}

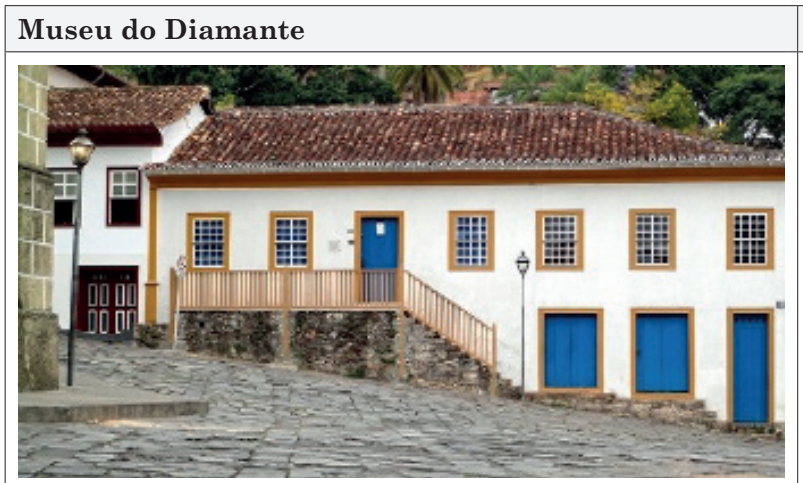

Breve histórico e uso pelo turismo

Atual Museu do Diamante. Construída no século XVIII, sua importância histórica deve-se ao fato de ter sido a residência do inconfidente padre José de Oliveira e Silva Rolim, natural do Arraial do Tijuco e um dos principais personagens da Inconfidência Mineira (1789) (IPHAN, 2017). É localizado no centro da cidade de Diamantina, é aberto ao público de terça-feira a sábado das 10:00 às 17:00 e aos domingos de 09:00 às 13:00. Possui visita guiada e não possui taxa de visitação

Fonte: Galeria do IPHAN

\section{POSSIBILIDADES}

1 - Diamantina tem uma forte ligação com o garimpo e o Museu do Diamante existente na cidade é um local que faz referência a atividade mineradora, mas o acervo é bastante limitado, apenas uma sala é sobre o ciclo do diamante. As técnicas de som, iluminação e imagens seriam uma de forma interessante de aguçar os sentidos do visitante e acrescentar uma experiência mais marcante, como por exemplo, uma apresentação audiovisual com referências de acontecimentos da época, atendendo ainda um publico estrangeiro. Conforme Tilden (2006) é importante não apenas instruir, mas provocar, estimulando a curiosidade do visitante, encorajando a exploração mais aprofundada do que está sendo interpretado. 2 - A recepção mais atrativa e convidativa, com o propósito de envolver o visitante com o lugar e convidá-lo para uma viagem no tempo. De acordo com Goodey (2002) é importante a criação de um mundo especial que valorize o patrimônio que está sendo exposto à visitação. Este mundo especial é a recordação que o visitante levará consigo em suas lembranças.

3 - Elaboração de textos interpretativos com linguagem adequada para todos os públicos e que contenha informações sobre o lugar.

4 - Sinalização indicativa bem planejada e que chame atenção do visitante para conhecer o museu. 5 - A utilização de mapas interativos no museu, também seria uma forma de sintonizar o visitante sobre vários aspectos da cidade Diamantina e do seu entorno. Poderiam ser colocados em painéis simples ou eletrônicos. Seria essencial para uma leitura da cidade e aguçar a curiosidade dos turistas em conhecer melhor o município de Diamantina.

6 - Informações em outros idiomas e em braile.

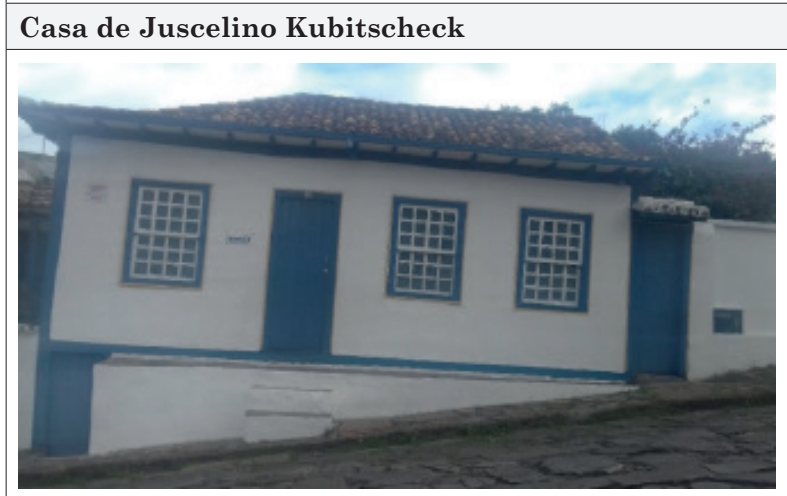

Fonte: A autora

\section{Breve histórico e usos pelo turismo}

É um antigo casarão muito preservado, onde Juscelino morou. Museu é composto por dois casarões, separados por um pátio. Na primeira casa, há documentos antigos sobre a vida do ex-presidente do Brasil, ata de formatura do primário e certidão de óbito de seu pai, João César de Oliveira, além de vários painéis contando a história de JK (IPHAN, 2017). Possui uma área externa espaçosa, e ao fundo tem uma biblioteca e outros objetos. Possui uma cantina para receber os visitantes para um café e disponibilizam artesanatos, revistas e livros para compra. Aberto de terça à domingo de 09: às 17:00. Taxa de visitação no valor de $\mathrm{R} \$ 10,00$ 


\section{POSSIBILIDADES}

1.As placas explicativas e a sinalização são muito importantes para um local que é repleto de história. Percebe-se que no museu possui poucas informações em língua estrangeira, Diamantina é uma cidade com reconhecimento mundial, o que torna necessário um cuidado com a qualidade das informações que são oferecidas para os diversos turistas frequentadores da cidade.

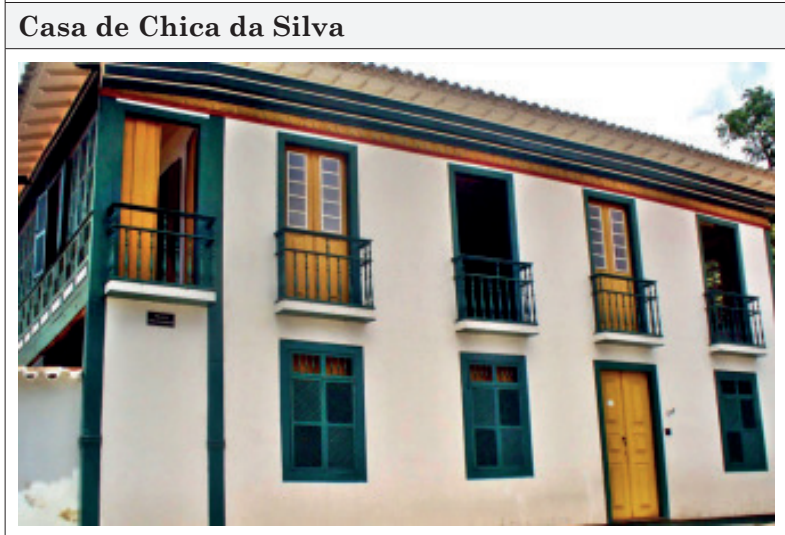

Fonte: Galeria do IPHAN

\section{Breve histórico e uso pelo turismo}

Residência do contratador de diamantes João Fernandes de Oliveira, que nela viveu em companhia da lendária escrava liberta Chica da Silva, provavelmente entre os anos de 1763 e 1771 (IPHAN, 2017). Localizada no centro histórico de Diamantina, onde funciona a atual sede do escritório técnico do IPHAN.O monumento é aberto ao público de terça-feira a sábado de 12:00 às 17:30 e nos domingos e feriados de 08:30 a 12:00. Não possui visita guiada, o acervo é pequeno e não é cobrada taxa de visitação.

\section{POSSIBILIDADES}

1 - É importante aproximar o visitante da história do local, abordando melhor a história da Chica da Silva e sua influencia em Diamantina, além da arquitetura da casa.

2 - Melhor recepção do turista na Casa da Chica da Silva.

3 - Recriar espaços e objetos de como seria a decoração, roupas, joias na casa de Chica da Silva.

4 - Utilização de placas e painéis interpretativos contendo informações que despertassem o interesse do público sobre a figura de Chica da Silva no meio social, cultural e político.

5 - Apresentar ao visitante o passado, de forma lúdica, através de teatros e saraus, retratando assuntos importantes da época.

6 - Placas Autoguiadas para que o visitante tenha mais autonomia.

7 - Utilização da tecnologia para auxiliar as visitações, como vídeos retratando os filmes sobre Chica, lendas.

8 - Placas interpretativas contendo informações sobre a arquitetura, a Capela de Chica, o Chafariz na área externa, quintal etc.

9 - Melhor aproveitamento da área externa que é bem ampla, (oficinas para turistas e comunidade local, divulgação dos trabalhos de artistas locais, como exposição de arte, artesanato, livros) 10 - Criar uma lojinha de souvenirs com produtos exclusivos de Chica da Silva (parceria com artistas locais) considerando os aspectos legais de comercialização. 


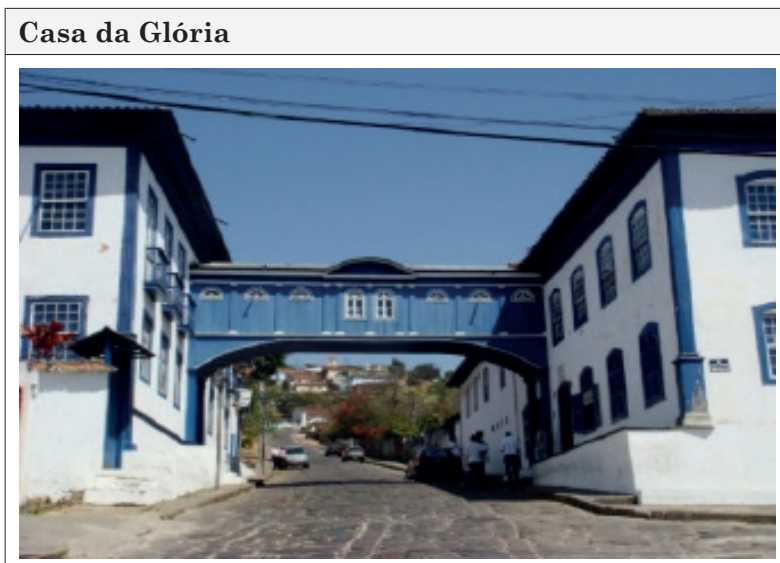

Fonte: Galeria do IPHAN
Breve histórico e uso pelo turismo

A casa da Glória está localizado em Diamantina (MG), possui um núcleo de pesquisa em uma casa histórica, tem sua sede principal em um conjunto de dois casarões, de rara beleza, situados em lados opostos da rua e interligados por um passadiço, conhecido como o "Passadiço da Glória" (IGC, 2017). Tem por objetivo principal dar suporte as atividades de ensino, pesquisa e extensão do Instituto de Geociências e de outras unidades da UFMG, além do resgate da memória, através de programas e projetos específicos, buscando sempre a cooperação e a parceria de órgãos e instituições públicas e privadas (IGC, 2017). O horário de funcionamento é de segunda-feira à domingo: 9:00h - 17:00h. Visita autoguiada e não possui taxa de visitação.

\section{POSSIBILIDADES}

1 - O Instituto Casa da Glória foi o único lugar que possui algumas ações de interpretação do patrimônio. 2 - O museu possui recursos interpretativos para os visitantes, como audiofone, onde são relatados o cotidiano das internas naquela época. Uma estratégia interessante para aproximar o visitante da história. A casa utiliza princípios metodológicos que de acordo com Tilden (1957), é importante sempre focalizar os sentidos dos visitantes, de forma a estabelecer a conscientização pessoal sobre determinadas característica do ambiente.

3 - A casa possui um totem contendo informações sobre a história do monumento, o centro de Geologia Eschwege, pontos de interesse para a visitação e eventos que a acontecem no instituto. A casa também possui placa interpretativa autoguiada e no início da visita é apresentado ao visitante um vídeo contendo um breve histórico sobre a Casa da Glória e a sua função atualmente. Que de acordo com Goodey (2002) é importante para guiar o visitante, que vai precisar de um período de ajuste antes de começar a visita, a Casa da Glória oferece uma sala adequada para esses fins.

3 - Possui ambiente agradável e recepção aconchegante, importante para receber o visitante de forma especial, a Casa da Glória apresenta uma entrada iluminada e com atendente simpática.

4 - Poderia ser utilizado de mídias interativas no instituto de geociências, como slides com projeções para os visitantes conhecerem de uma forma mais dinâmica os tipos de rochas, curiosidades e todo o processo. Informações em outros idiomas além das que possuem no totem, e informações em braile, para contemplar a diversidade do público que visita o instituto.

Quanto aos monumentos religiosos, optamos por propor sugestões que de forma geral contribuam para melhorias nas técnicas e ferramentas de intepretação patrimonial, considerando que os três monumentos estudados, apresentaram as mesmas deficiências, conforme tabela 09. 


\section{Tabela 9: Possibilidades interpretação patrimonial nos monumentos religiosos}

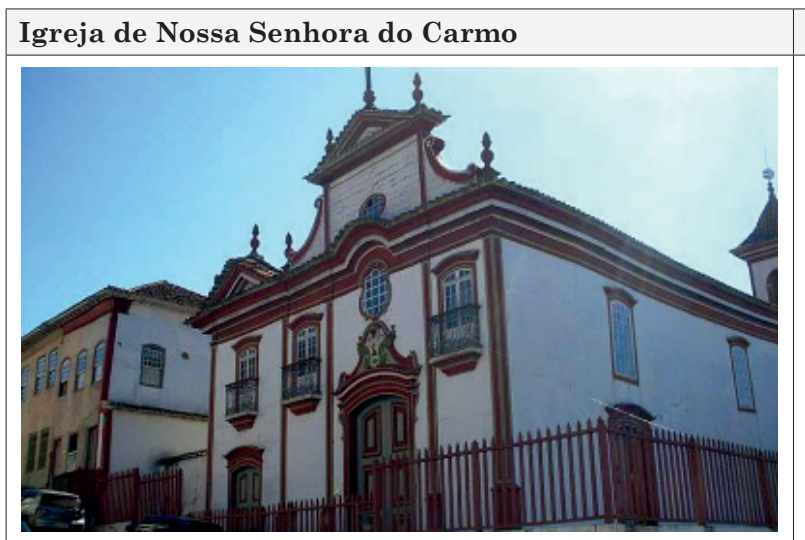

História e uso pelo turismo

Uma das mais significativas da região, com uma arquitetura graciosa ao mesmo tempo imponente com a delicadeza e o vigor da decoração pictórica (IPHAN, 2017). É localizada no centro histórico de Diamantina, para visitar o monumento é cobrada uma taxa de $\mathrm{R} \$ 3,00$ e não possui visita guiada, pois é a ordem que é responsável pela igreja. A Igreja é aberta na terça-feira, quarta, quinta e sábado no horário de 13:00 às 17:00 e não é permitido fotografar em seu interior.

\section{Fonte: Galeria do IPHAN}

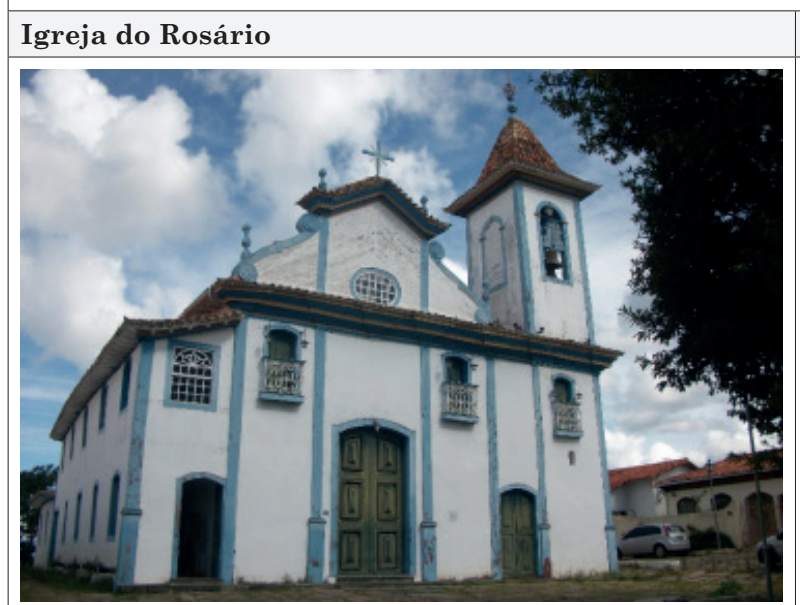

Breve histórico e uso pelo turismo

Uma das mais antigas de Diamantina. Entre 1771 e 1772, os irmãos do Rosário contrataram o mestre Manuel Gonçalves para a construção da igreja. A pintura do arco-cruzeiro e do forro formam um conjunto extremamente harmônico, conseguido a partir da intervenção de José Soares de Araújo, autor da pintura e douramento dessas áreas (IPHAN, 2017). Localizada no centro histórico de Diamantina, é aberta ao público de terça-feira a sábado de 13:00 às 17:00 e nos domingos e feriados de 09:00 às 13:00. Possui visita guiada e taxa de visitação no valor de $\mathrm{R} \$ 5,00$

Fonte: A autora

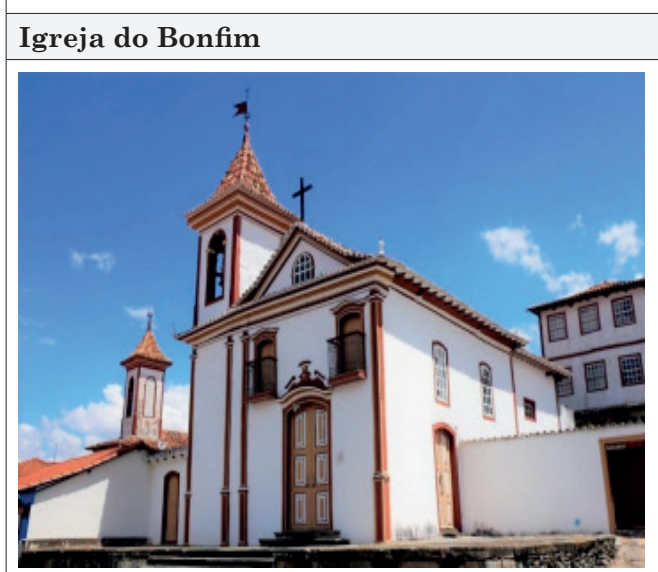

Foto: Galeria do IPHAN

Fonte: Elaborado pela autora a partir de dados obtidos de pesquisa de demanda turística 


\section{Possibilidades de interpretação nas igrejas}

1) Nas igrejas em geral deve ser melhorada a sinalização. Seria viável colocar placas de sinalização interpretativa na parte externa, com informações sucintas e alguma imagem do interior da igreja, para chamar a atenção do visitante e instiga-lo a visitar o monumento. É importante vincular textos com imagens, pois a mensagem é transmitida de uma maneira mais rápida e objetiva.

2) O concerto do órgão histórico Almeida Silva/Lobo de Mesquita é um evento musical que ocorre na igreja do Carmo e que faz parte do calendário de eventos da cidade. Uma ação interessante de vincular a música clássica com o ambiente de uma igreja secular, agregando um valor especial e único do local.

3) A utilização de uma trilha sonora durante a visitação às igrejas seria uma proposta interessante para oferecer ao visitante, uma visita marcante e inspiradora. Harmonizando o ambiente sagrado com as músicas sacras, adequados para o ambiente. E com horários estipulados para a entoação.

4) Utilização de áudio guia, contendo informações em outros idiomas acerca do contexto histórico da igreja.

5) Totem e placas interpretativas contendo informação sobre a igreja, esclarecimentos sobre arquitetura, pinturas artística, história da arte, lendas, curiosidades.

6) A igreja do Carmo poderia ter uma recepção com guias para recepcionar e prestar esclarecimentos sobre o potencial cultural do local.

7) Folder com informações sobre a igreja visitada.

Por fim, estes dados revelam a importância de ferramentas adequadas para interpretação do patrimônio como alternativa para valorização da história local e reconhecimento de elementos sensoriais que costumam passar despercebidos diante dos olhares de seus visitantes, visando de uma maneira dinâmica e interativa, permitir uma transformação cultural, ao mesmo tempo em que ajuda na preservação do patrimônio histórico de uma localidade

\section{Considerações finais}

A cidade de Diamantina é como se fosse um "baú" antigo repleto de memórias que foram se acumulando com o passar dos anos. Diamantina se apresenta como um lugar de intercâmbio cultural, uma cidade detentora de histórias importantes, cultura e um patrimônio histórico cultural preservado.

É importante considerar que cidades Patrimônios da Humanidade, como Diamantina e outras que possui um rico acervo histórico e arquitetônico, podem ser apresentar como destinos motivadores de deslocamentos de pessoas, e que, portanto, necessitam de suporte e informações de qualidade que promovam o reconhecimento e pertencimento ao patrimônio preservado. Os dados revelados nesta pesquisa permitiram compreender quais as carências dos turistas que visitam Diamantina em se tratando da comunicação mais interativa nos espaços de memória. Estes visitantes tiveram a oportunidade de apontar as falhas e também contribuir para uma melhor qualidade da atividade turística. A pesquisa revelou ainda que as informações sobre a história do lugar precisam ser organizadas, pesquisadas adequadamente e inseridas nos espaços de memória, que são os monumentos históricos. Outro ponto importante observado é em relação à linguagem, que deve ser mais acessível para os mais diversos públicos, levando em consideração a faixa etária, pessoas com algum tipo de necessidade especial, para que todos os visitantes possam compreender a importância do bem cultural no contexto histórico e tenha autonomia para fazer uma melhor leitura da cidade.

A falta de ações interpretativas podem tornar os monumentos espaços vazios de emoção. É imprescindível que o conjunto de informações expostas no monumento vão além de apenas informar, mas que toque os sentidos dos visitantes, provoque sensações, curiosidades e forneça conhecimento de uma forma lúdica. O planejamento adequado aliado as técnicas de interpretação do patrimônio, poderia facilitar uma comunicação mais dinâmica entre o visitante e a cultura local, valorizando o patrimônio local e o respeito com o mesmo. Para Bazán (2014) a interpretação ocorre no interior de cada pessoa, é o que intelectual e emocionalmente consegue conectar-se com o bem patrimonial.

No decorrer do trabalho podemos perceber que apenas algum dos monumentos históricos pesquisados tem alguma ação voltada para a interpretação do patrimônio que interaja com o visitante e o aproxime de uma parte da história da cidade que foi compactada no monumento, como recursos tecnológicos, guias 
e placas interpretativas, além de ações do poder público para manutenção dos monumentos históricos para visitação turística.

A interpretação patrimonial para a cidade de Diamantina seria uma proposta inovadora e bastante viável para a realidade da cidade, que tem uma cultura arraigada. Se o visitante for recebido adequadamente e tiver experiências significativas com a cultura, este vai reproduzir a experiência para outras pessoas.

Por fim nesta pesquisa, observa-se que quando se trata de sítios históricos e detentores de recursos culturais, projetos e ações voltados para gestão turísticas se tornam essenciais, como forma de permitir a valorização do patrimônio. O envolvimento de todos os atores locais é de suma importância: o poder público, poder privado, moradores locais, especialistas de áreas distintas, que em conjunto poderão contribuir para que as ações sejam assertivas. A partir desse estudo pode-se aferir que a interpretação do patrimônio nas cidades patrimônios poderia contribuir para auxiliar na qualidade da atividade turística e gerar benefícios sociais, econômicos e culturais, bem como possibilitar que o turismo cumpra o seu papel intermediador entre o patrimônio e visitantes, permitindo uma maior consciência cultural e um melhor aproveitamento dos recursos patrimoniais pelo turismo.

\section{Bibliografía}

Albano, Celina; Murta, Stela Maris

2002. Interpretar o Patrimônio: um exercício do olhar. Belo Horizonte: Ed. UFMG.

Barretto, Margarita

2005. Planejamento responsável do turismo. Papirus Editora.

Bazán, Héctor Guillermo

2014. La interpretación del patrimonio geomorfológico en los Picos de Europa: una propuesta para su aprovechamiento didáctico y geoturístico. Disponível em: <http://uvadoc.uva.es/handle/10324/6513> Acesso em janeiro de 2017

Beorlegui, Juan José Hervias

Intepretación del Patrimonio através del analisis de las técnicas usadas en el museo de Jamtli. Universitat de Barcelona. Facultat d'Educació. Programa de doctorado (EFES) Didáctica de las Ciencias Soclaies y de Patrimonio, Barcelona, 2016

Brochu, L.; Merriman T.

2012. Personal Interpretation (Kindle Edition). Fort Collins: Heartfelt Publications.

Camargo, Haroldo L.

2004. Patrimônio e Turismo, uma longa relação: história, discurso e práticas. Revista lazer e turismo-revista eletrônica COEAE. Unisantos-Universidade católica de Santos. Disponível em: <http://www. unisantos.br/pos/revistapatrimonio/artigosdc19.html?cod=33>Acesso em jan de 2016

Cardozo, Poliana Fabiula de; Melo, Alessandro

2015. Patrimônio, Turismo cultural e educação patrimonial. Educação e Sociedade, v. 36, n. 133.

Disponível em: http://www.scielo.br/pdf/es/v36n133/1678-4626-es-36-133-01059.pdf Acesso em 2017

Choay, Françoise

2006. A alegoria do patrimônio. São Paulo: Estação Liberdade; Unesp.

Costa, Flávia Roberta

2009. Turismo e patrimônio cultural: Interpretação e qualificação. São Paulo; Senac São Paulo: Edições SESC SP.

Dencker, Ada de Freitas Maneti

1998. Pesquisa em turismo: planejamento, métodos e técnicas. 9 ed. São Paulo: Futura.

Farias, Eny Kleyde V.

2002. A construção de atrativos turísticos com a comunidade. In: Albano, Celina; Murta, Stela Maris.

(Coord.) Interpretar o Patrimônio: um exercício do olhar. Belo Horizonte: Ed. UFMG,. P. 59-73.

Goodey, Brian.

2002. A interpretação do Sítio Turístico: desenho e atividade. In: Albano, Celina; Murta, Stela. Maris. (orgs). Interpretar o patrimônio: um exercício do olhar. Belo horizonte: Ed. UFMG. Território Brasilis. Instituto do Patrimônio Histórico e Artístico Nacional

1999. Proposta de inscrição de Diamantina na lista de patrimônio mundial. Anexo 09. Disponível em: $<$ http://portal.iphan.gov.br/uploads/ckfinder/arquivos/Dossi\%C3\%AA\%20Diamantina.pdf $>$ Acesso em 2016 
Morales, Jorge

2012. apud Téllez, Geiser Perera, García C. María Elena Betancourt. Técnicas de interpretación para la gestión turística en los recorridos de ciudad: el caso de la ciudad de Camagüey. Centro de Estudios Multidisciplinarios del Turismo, Facultad de Ciencias Económicas y Jurídicas, Universidad de Camagüey Ignacio Agramonte Loynaz, Retos de la Dirección 2016; 10(1): 94-113

Ministério do Turismo

2006. Turismo Cultural. Disponível em: <http://www.turismo.gov.br/sites/default/turismo/o_ministerio/ publicacoes/downloads_publicacoes/Turismo_Cultural_Versxo_Final_IMPRESSxO_.pdf $>$ Acesso em jan de 2017

Murta, Stela Maris; Goodey, Brian

2005. Interpretação do patrimônio para o turismo sustentado - Um Guia. Belo Horizonte: Sebrae MG, 114p. Pires, Fabiana Mendonça

2006. A interpretação patrimonial na relação entre o sujeito e o atrativo: percepções dos turistas e dos moradores sobre a interpretação do patrimônio edificado em Tiradentes. Disponível em: $<$ http:// livros01.livrosgratis.com.br/cp155801.pdf>. Acesso em 2016

Tilden, Freeman

1957. Interpreting our heritage. The University of North Carolina Press, Chapel Hill, NC. Sevilla.

Tomazzoni, Edegar Luis

2009. Turismo e desenvolvimento regional: dimensões, elementos e indicadores. Educs. Disponível em: $<$ https://edisciplinas.usp.br/pluginfile.php/218480/mod_resource/content/1/TOMAZZONI\%2C\%20 Edegar\%20L.\%20LIVRO\%20Turismo\%20e\%20Desenvolvimento\%20Regional\%20\%28Educs\%2C\%20 2009\%29.pdf>. Acesso em 2016

Téllez, Geiser Perera, García C. María Elena Betancourt

2016. Técnicas de interpretación para la gestión turística en los recorridos de ciudad: el caso de la ciudad de Camagüey. Centro de Estudios Multidisciplinarios del Turismo, Facultad de Ciencias Económicas y Jurídicas, Universidad de Camagüey Ignacio Agramonte Loynaz, Retos de la Dirección; 10(1): 94-113 